https://doi.org/10.30910/turkjans.698783

\begin{tabular}{c}
\hline TÜRK \\
TARIM ve DOĞA BILIMLERI \\
DERGISi \\
\hline \hline
\end{tabular}

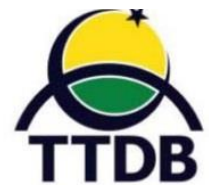

www.dergipark.gov.tr/turkjans

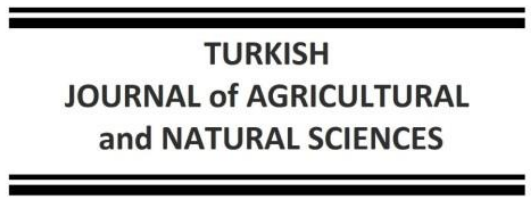

Araştırma Makalesi

\title{
Keban Baraj Gölü Çemişgezek Bölgesinde (4. Bölge) Avcılığı Yapılan Bazı Balıklarda Endohelmintlerin Araştırılması
}

\author{
Burcu AKTÜRK, Engin ŞEKER, Ayşegül PALA* \\ Munzur Üniversitesi, Su Ürünleri Fakültesi, Tunceli \\ *Sorumlu Yazar: aysegulpala@munzur.edu.tr
}

\section{Geliş Tarihi: 09.03.2020 Düzeltme Geliş Tarihi: 15.10.2020 Kabul Tarihi: 15.10.2020}

\section{$\overline{O ̈ z}$}

Bu çalışma, Temmuz 2016 -Aralık 2016 tarihleri arasında Keban Baraj Gölü Çemişgezek Bölgesi (4. Bölge)'nden avlanan 52 adet Cyprinus carpio (Linnaeus, 1758), 49 adet Capoeta trutta (Heckel, 1843), 53 adet Lucio barbus mystaceus (Pallas, 1814) ve 56 adet Lucio barbus esocinus (Heckel, 1843) olmak üzere toplam 210 balık üzerinde yürütüldü. İncelenen balıkların 173'ünde üç parazit türü tespit edildi. Yapılan parazitolojik incelemede C. carpio' nun göz sıvısında Diplostomum sp., bağırsağında Khawia sinensis olmak üzere 2 parazit türü teşhis edildi. C. trutta, L. barbus esocinus ve L. barbus mystaceus'un göz sıvılarında Diplostomum sp., bağırsaklarında ise Neoechinorhynchus rutili olmak üzere 2 parazit türü teşhis edildi. Elde edilen sonuçlara göre incelenen 4 balık türünde Diplostomum sp.'nin \%73.33 yaygınlık oranı ve 8.97 yoğunluk ile en baskın parazit türü olduğu belirlendi. Tespit edilen diğer parazit türleri N.rutili ve K.sinensis'in yaygınlık oranları sırasıyla $\% 40.95$ ve \%15.38, yoğunlukları ise 7.11 ve 2.25 olarak saptandı.

Anahtar kelimeler: Çemişgezek, parazit, balık, endohelmint, Keban Baraj Gölü

\section{Investigation of Endohelmints in The Fishes Hunted in Keban Dam Lake Çemişgezek}

\section{Region (4th Region)}

\begin{abstract}
This study was carried out on 210 fish, which were 52 Cyprinus carpio (Linnaeus, 1758), 49 Capoeta trutta (Heckel, 1843), 53 Lucio barbus mystaceus (Pallas, 1814) and 56 Lucio barbus esocinus (Heckel, 1843), which were hunted in the Keban Dam Lake Çemişgezek Region (4th Region) between July 2016 and December 2016. Three parasite species were encountered in 173 infested fish. After autopsy, two parasite types as Diplostomum sp. in the eyes fluid, Khawia sinensis in the intestine were identified in C. carpio. Two parasite species were identified in C. trutta, L. barbus esocinus and L. barbus mystaceus: Diplostomum sp. in eye fluids and Neoechinorhynchus rutili in their intestines. According to the results, it was determined that Diplostomum sp. was the most dominant parasite species with $73.33 \%$ prevalence and 8.97 density in 4 fish species examined. The prevalence rates of other identified parasite species N.rutili and K.sinensis were $40.95 \%$ and $15.38 \%$, respectively, and densities were 7.11 and 2.25 respectively.
\end{abstract}

Key words: Cemisgezek, parasite, fish, endohelmint, Keban Dam Lake

\section{Giriş}

Ülkemizde balık üretiminin artışıyla birlikte balık hastalıkları konusu da önem kazanmıştır. Bu nedenle üretimi yapılan balık türlerinin, paraziter hastalıklarının belirlenmesi kadar, aynı bölgedeki iç su kaynaklarında bulunan balıkların parazit faunalarının da bilinmesi gerekli hale gelmiştir (Karatoy ve Soylu, 2006). Herhangi bir bölgede balıklardaki parazit faunasının bilinmesi, kültürü yapılan balık stokları üzerindeki koruyucu ve tedavi edici uygulamaların yapılmasına olanak sağlayacaktır (Selver ve ark., 2013). 
Parazitler, balıkların besin değerlerini düşürmelerinin yanı sıra, büyüme, çoğalma ve beslenme özelliklerini de olumsuz yönde etkilemektedir (Özan ve ark., 2006; Serdar ve ark., 2018). Balık hastalıkları içinde önemli paraziter gruplardan biri olan helmintler, balıkların iç ya da dış organların da yaşayan, uzun, yassı, yuvarlak veya şerit şeklindeki kurtçuklardır. Bir veya birden fazla ara konakçıda gelişmelerini tamamlayarak, olgun parazit halini alırlar. Helmintler gelişimleri esnasında konakçı balıklarda; iştah azalması, aşırı mukoz salgılaması, renk açılması, yüzme bozukluğu ve dokularda yangı ile hemorajilerin oluşması gibi etkilere neden olmakta özellikle bağırsaklardaki yangı ve dejenerasyona, balık ölümlerine dolayısıyla ekonomik kayıplara yol açmaktadır ( Molnar, 1987; Hoole ve ark., 2001).

Keban Baraj gölünün farklı bölgelerinde balık parazitleri ile ilgili pek çok çalışma yapıımıştır (Sarıeyyüpoğlu ve Sağlam, 1991; Sağlam, 1991; Özdemir ve Sarıeyyüpoğlu,1993; Türk ve Dörücü, 2000; Dörücü ve ark., 2002; Sağlam ve Sarıeyyüpoğlu, 2002; Dörücü ve İspir, 2005). Karabulut (2009), çalışma alanımız olan Keban Baraj Gölü Çemişgezek Bölgesini de içeren çalışmasında C. carpio'da endohelmintleri tespit etmiştir. Bunun dışında Keban Baraj Gölü Çemişgezek Bölgesi (4.Bölge) avlak sahasında avlanabilen bazı farklı türleri kapsayan balık parazitleri üzerine kapsamlı bir çalışmaya rastlanmamıştır. Bu çalışma ile bu alanda avcılığı yapılan bazı balıklarda görülen endohelmintlerin tanınmasını sağlamak, parazit türleri ve sayıları ile yoğunluğu, bolluğu ve yaygınlığını tespit etmek amaçlanmıştır.

\section{Materyal ve Metot}

Çalışma Keban Baraj Gölü içerisinde yer alan Çemişgezek Bölgesi (4. Bölge) avlak sahasında gerçekleştirildi (Şekil 1).

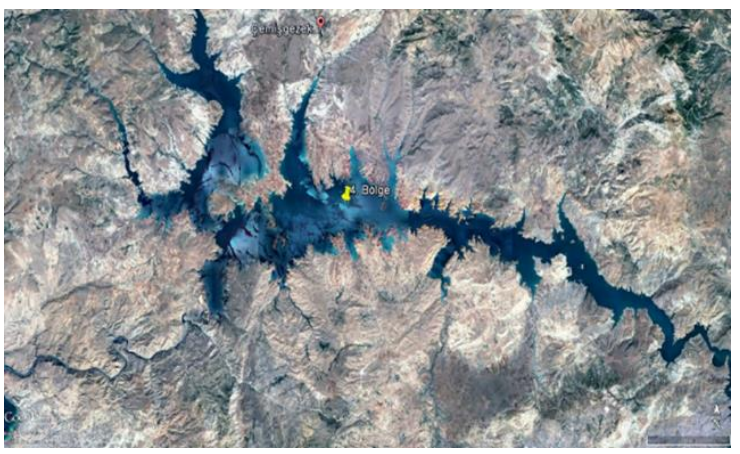

Şekil 1. Araştırma Bölgesi (Keban Baraj Gölü Çemişgezek Bölgesi (4. Bölge))

Bu çalışma Temmuz 2016 ve Aralık 2016 tarihleri arasında Keban Baraj Gölü Çemişgezek
Bölgesinde (4.Bölge) en çok avcılığı yapılan dört tür balık; Cyprinus carpio (Sazan), Lucio barbus esocinus (Turna), Lucio barbus mystaceus (Küpeli), Capoeta trutta (Karabalık)' üzerinde yürütüldü. Avlamada $70 \mathrm{~mm}$ (Sazan), 50-90 mm (Turna, Küpeli) ve $42 \mathrm{~mm}$ (Karabalık) göze genişliğine sahip galsama ağları kullanıldı.

Çalışmada, 52 adet C. carpio, 49 adet $C$. trutta, 53 adet $L$. barbus mystaceus ve 56 adet $L$. barbus esocinus olmak üzere toplam 210 balık endohelmint yönünden incelendi. Laboratuvara getirilen balıkların önce Geldiay ve Balık (2007)'a göre tür teşhisleri yapıldı. Balıkların total boy ve ağırlıkları ölçülerek kaydedildi. Daha sonra, Arda ve ark., (2005)'e göre nekropsisi yapılan balıkların iç organları çıkarılarak petri kutularına bırakıldı. Vücut boşluğu ve iç organlar öncelikle çıplak gözle makroskobik olarak incelendi ve daha sonra ışık kaynağı ile desteklenmiş binoküler stereo mikroskop altında iç organların parazit incelemesi yapıldı. Bunu takiben kalp, hava kesesi ve safra kesesi diseksiyon iğnesi ile ezilerek, karaciğer ise küçük parçalar halinde lam lamel arasında ezilerek incelendi. Bağırsaklar diseksiyon makası yardımı ile açılıp içeriğinin dışarı çıkması sağlanarak tuz oranı $\% 0,9$ olan fizyolojik tuzlu suyun olduğu petri kutularına alındı ve parazit incelemesi yapıldı. Bağırsaklarda bulunan parazitler içerisinde serum fizyolojik bulunan başka bir petri kabına alınarak parazit üzerindeki dışkı ve diğer yabancı partiküllerin uzaklaştırılması sağlandı. Pens ve bisturi yardımıyla çıkarılan göz mercekleri de mikroskop altında incelendi.

Bulunan parazitler sayıldı ve Kennedy (1974), Ekingen (1983), Hoffman (1967) göre teşhisleri yapıldı.

Bush ve ark., (1997) belirtiği şekilde, parazitlerin ortalama yoğunluk, yaygınlık ve ortalama bolluk değerlerinin hesaplanmasında aşağıdaki formüller kullanıldı.

- Ortalama yoğunluk = Toplam parazit sayısı / Parazitli balık sayısı

- Yaygınlık = Parazitli balık sayısı / Toplam balık sayısı x 100

- Ortalama bolluk = Toplam parazit sayısı / Toplam balık sayısı

\section{Bulgular ve Tartışma}

Çalışmada, Temmuz 2016-Aralık 2016 tarihleri arasında Keban Baraj Gölü Çemişgezek Bölgesinden (4. Bölge) avlanan 52 adet C. carpio, 49 adet $C$. trutta, 53 adet $L$. barbus mystaceus ve 56 adet $L$. barbus esocinus olmak üzere toplam 210 balık üzerinde yapılan incelemede Diplostomum sp., $K$. sinensis ve $N$. rutili olmak üzere üç farklı parazit türü teşhis edildi. 
Incelenen balıklar ve balıkların parazitik durumları Tablo 1'de verilmiştir. İncelenen $52 \mathrm{C}$. carpio'dan 47, 49 C. trutta' dan 46, 56 L. barbus esocinus' $\tan 40,53$ L. barbus mystaceus' un ise 40 tanesinin enfeste olduğu tespit edilmiştir. C. carpio' nun göz sıvısında Diplostomum sp., bağırsağında $K$. sinensis olmak üzere 2 parazit türü teşhis edilmiştir C. trutta' nın göz sıvısında Diplostomum sp. bağırsağında $N$. rutili olmak üzere 2 parazit türü saptanmıştır. L. barbus mystaceus' un göz sıvısında Diplostomum sp., bağırsağında N. rutili olmak üzere 2 parazit türü tespiti yapılmıştır. Benzer şekilde, $L$. barbus esocinus'un göz sıvısında Diplostomum sp. bağırsağında $N$. rutili türü teşhis edilmiştir. Diplostomum sp. ve $K$. sinensis ile enfeste olan $C$. carpio' da toplam 415 parazit, Diplostomum sp. ve N. rutili ile enfeste olan C. trutta' da toplam 513 parazit, Diplostomum sp. ve $N$. rutili ile enfeste olan L. barbus esocinus' da toplam 465 parazit, Diplostomum sp. ve $N$. rutili ile enfeste olan $L$. barbus mystaceus' da ise 609 parazit tespiti yapıldı ve genel toplamda 2002 parazit tespit edilmiştir. (Çizelge 1).

Balık türlerinde tespiti yapılan parazitlerin aylara enfeste durumları Çizelge 2' de verilmiştir.

Çizelge 1. Parazitlerin konakta bulunduğu yaşam alanı ve toplam sayıları

\begin{tabular}{|c|c|c|c|c|c|c|c|}
\hline Balık türü & $\begin{array}{l}\text { İncelenen } \\
\text { balık sayısı }\end{array}$ & $\begin{array}{c}\text { Enfeste } \\
\text { balık sayısı }\end{array}$ & Parazit türleri & $\begin{array}{c}\text { Parazitin balıkta } \\
\text { bulunduğu yaşam } \\
\text { alanı }\end{array}$ & $\begin{array}{c}\text { Parazitli } \\
\text { balık sayısı }\end{array}$ & Parazit sayısı & $\begin{array}{c}\text { Toplam } \\
\text { parazit } \\
\text { sayısı }\end{array}$ \\
\hline \multirow{3}{*}{ C. carpio } & \multirow{3}{*}{52} & \multirow{3}{*}{47} & Diplostomum sp. & Göz sIVISI & 45 & 407 & \\
\hline & & & K. sinensis & Bağırsak & 6 & 8 & 415 \\
\hline & & & Diplostomum sp. & Göz sıvısı & 40 & 206 & \multirow{3}{*}{513} \\
\hline & & & & & & & \\
\hline C. trutta & 49 & 46 & N.rutili & Bağırsak & 34 & 307 & \\
\hline \multirow{3}{*}{$\begin{array}{l}\text { L. barbus } \\
\text { esocinus }\end{array}$} & \multirow{3}{*}{56} & \multirow{3}{*}{40} & Diplostomum sp. & Göz sIVISI & 34 & 344 & \multirow{3}{*}{465} \\
\hline & & & & & & & \\
\hline & & & N.rutili & Bağırsak & 25 & 121 & \\
\hline \multirow{3}{*}{$\begin{array}{l}\text { L. barbus } \\
\text { mystaceus }\end{array}$} & \multirow{3}{*}{53} & \multirow{3}{*}{40} & Diplostomum sp. & Göz sIVISI & 35 & 425 & \multirow{3}{*}{609} \\
\hline & & & & & & & \\
\hline & & & N.rutili & Bağırsak & 27 & 184 & \\
\hline Toplam & 210 & 173 & & & 246 & & 2002 \\
\hline
\end{tabular}

Çizelge 2. Balık türlerinin aylara göre enfeste durumu

\begin{tabular}{|c|c|c|c|c|c|c|c|c|c|c|c|c|}
\hline \multirow[b]{2}{*}{ Aylar } & \multicolumn{4}{|c|}{ İncelenen balık türleri ve sayıları } & \multicolumn{4}{|c|}{ Tespiti yapılan parazitli balık sayısı } & \multicolumn{4}{|c|}{$\begin{array}{c}\text { Balıklarda tespiti yapılan toplam } \\
\text { parazit sayısı }\end{array}$} \\
\hline & $\frac{\frac{0}{2}}{8}$ & 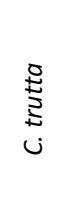 & 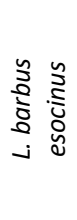 & 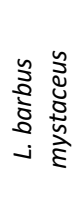 & $\frac{0}{\frac{2}{2}}$ & 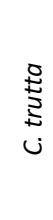 & 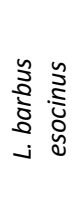 & 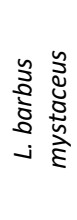 & $\begin{array}{l}\frac{0}{2} \\
\frac{0}{2} \\
ن\end{array}$ & 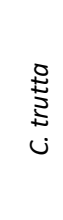 & 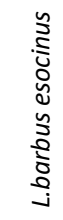 & 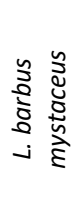 \\
\hline Temmuz 2016 & 10 & 8 & 10 & 8 & 10 & 7 & 7 & 6 & 53 & 74 & 91 & 91 \\
\hline Ağustos 2016 & 9 & 9 & 8 & 10 & 8 & 8 & 5 & 7 & 43 & 55 & 63 & 98 \\
\hline Eylül 2016 & 9 & 8 & 10 & 9 & 7 & 7 & 8 & 6 & 70 & 81 & 70 & 90 \\
\hline Ekim 2016 & 9 & 8 & 8 & 8 & 7 & 8 & 5 & 6 & 84 & 121 & 72 & 77 \\
\hline Kasım 2016 & 8 & 8 & 10 & 10 & 8 & 8 & 7 & 8 & 106 & 69 & 68 & 157 \\
\hline Aralık 2016 & 7 & 8 & 10 & 10 & 7 & 8 & 7 & 5 & 59 & 113 & 101 & 96 \\
\hline Toplam & 52 & 49 & 56 & 53 & 47 & 46 & 39 & 38 & 415 & 513 & 465 & 609 \\
\hline
\end{tabular}


Incelenen balıklarda parazitlerin yoğunluğu, yaygınlığı ve bolluğu Tablo 3'te verilmiştir. Yapılan parazitolojik muayenelerde Diplostomum sp. ile enfeste olan 45 C. carpio'da toplam 407 adet Diplostomum sp. bulunmuş olup, Diplostomum sp.'nin yoğunluğu 9.04, yaygınlığı \%86.53, bolluğu ise 7.82 olarak hesaplanmıştır. $K$. sinensis ile enfeste olan 8 C. carpio'da 18 adet $K$. sinensis bulundu ve yoğunluğu 2.25, yaygınlığı \%15.38, bolluğu ise 0.34 olarak tespit edilmiştir (Tablo 3 ).

C. trutta'da 40 birey Diplostomum sp. ile enfeste olmuş olup, toplam 206 adet Diplostomum sp. bulundu. Diplostomum sp.'nin yoğunluğu 5.15, yaygınlığı \%81.63 bolluğu ise 4.20 olarak hesaplanmıştır. 34 tane C. trutta 'yı enfeste eden N. rutili'nin toplam parazit sayısı 307 olup, yoğunluğu 9.02, yaygınlığı \% 69.38, bolluğu ise 6.26 olarak tespit edilmiştir (Tablo 3).

L. barbus esocinus'da 34 birey Diplostomum sp. ile enfeste olurken, toplam 344 adet
Diplostomum sp.'nin yoğunluğu 10.11, yaygınlığı \%60.71 bolluğu ise 6.14 olarak hesaplanmıştır. 25 adet $N$. rutili ile enfeste balık sayısı bulunurken toplam 121 adet $N$. rutili tespit edilmiştir ve yoğunluğu 4.84, yaygınlığı \% 44.64, bolluğu ise 2.16 olarak hesaplanmıştır (Tablo 3 ).

Diplostomum sp. ile enfeste olan 35 tane L.barbus mystaceus'da toplam 425 adet Diplostomum sp. bulunmuş ve Diplostomum sp.'nin yoğunluğu 12.14 yaygınlığı \%66.03 bolluğu ise 8,01 olarak hesaplandı. 27 tane L.barbus mystaceus'u enfeste eden $N$. rutili'nin toplam sayısı 184 olup, yoğunluğu 6.81 , yaygınlığı \%50.94 ve bolluğu 3.47 olarak belirlenmiştir (Tablo 3).

Elde edilen veriler ışığında Diplostomum sp., ile toplam $154, N$. rutili ile toplam $86, K$. sinensis ile toplam 8 adet balığın enfeste olduğu görüldü. Parazit sayıları ise toplamda Diplostomum sp. için $1382, N$. rutili için $612, K$. sinensis için ise 18 olarak saptanmıştır (Çizelge 3 ).

Çizelge 3. Balıklarda tespit edilen parazitlerin yoğunluğu, yaygınlığı ve bolluğu

\begin{tabular}{|c|c|c|c|c|c|c|c|c|c|c|c|c|c|c|c|}
\hline \multirow[b]{2}{*}{$\begin{array}{l}\text { Balık } \\
\text { Türleri }\end{array}$} & \multicolumn{3}{|c|}{$\begin{array}{l}\text { Enfeste balık } \\
\text { sayısı }\end{array}$} & \multicolumn{3}{|c|}{$\begin{array}{c}\text { Bulunan parazit } \\
\text { sayısı }\end{array}$} & \multicolumn{3}{|c|}{ Yoğunluk } & \multicolumn{3}{|c|}{$\begin{array}{l}\text { Yaygınlık } \\
\text { (\%) }\end{array}$} & \multicolumn{3}{|c|}{ Bolluk } \\
\hline & $\begin{array}{l}\frac{\xi}{5} \\
\frac{0}{\tilde{\omega}} \\
\frac{0}{0} \\
\frac{0}{0}\end{array}$ & 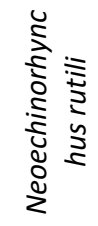 & 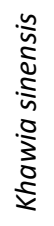 & 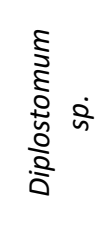 & 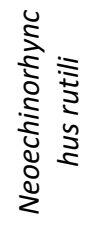 & 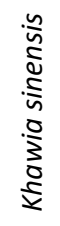 & 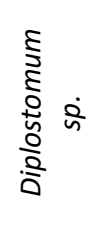 & 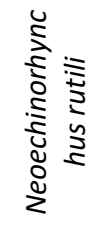 & 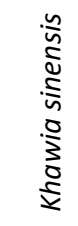 & $\begin{array}{l}\frac{5}{5} \\
\frac{5}{0} \\
\frac{2}{\tilde{n}} \\
\frac{2}{0} \\
\frac{0}{0}\end{array}$ & 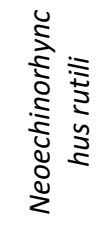 & 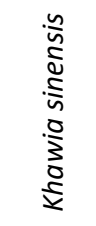 & $\begin{array}{l}\frac{5}{5} \\
\frac{\delta}{\tilde{n}} \\
\frac{0}{0} \\
\frac{0}{0}\end{array}$ & 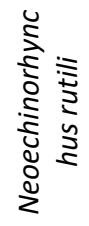 & $\begin{array}{l}\frac{n}{5} \\
\frac{2}{d} \\
\frac{5}{5} \\
\frac{0}{3} \\
\frac{3}{2} \\
\frac{5}{2}\end{array}$ \\
\hline C. carpio & 45 & - & 8 & 407 & - & 18 & 9.04 & - & 2.25 & 86.53 & - & 15.38 & 7.82 & - & $\begin{array}{l}0 . \\
34\end{array}$ \\
\hline C. trutta & 40 & 34 & - & 206 & 307 & - & 5.15 & 9.02 & - & 81.63 & 69.38 & - & 4.20 & 6.26 & - \\
\hline $\begin{array}{l}\text { L. barbus } \\
\text { esocinus }\end{array}$ & 34 & 25 & - & 344 & 121 & - & $\begin{array}{c}10.1 \\
1\end{array}$ & 4.84 & - & 60.71 & 44.64 & - & 6.14 & 2.16 & - \\
\hline $\begin{array}{l}\text { L. barbus } \\
\text { mystaceus }\end{array}$ & 35 & 27 & - & 425 & 184 & - & $\begin{array}{c}12.1 \\
4\end{array}$ & 6.81 & - & 66.03 & 50.94 & - & 8.01 & 3.47 & - \\
\hline Toplam & 154 & 86 & 8 & 1382 & 612 & 18 & 8.97 & 7.11 & 2.25 & 73.33 & 40.95 & 8.57 & 6.58 & 2.91 & $\begin{array}{l}0 . \\
09\end{array}$ \\
\hline
\end{tabular}

Bu çalışmanın sonuçları, Diplostomum sp.,'nin incelenen dört balık türünde de tespit edilmesi ve so yaygınlığa sahip olması nedeniyle bu parazitin dominant bir tür olduğunu göstermektedir. Benzer şekilde, Barata ve Dörücü (2014) Karakaya Baraj Gölü'nde yakalanan dört balık türünde baskın parazit türü olarak Diplostomum sp.,'yi tespit etmiştir. Kavak ve Şeker (2017) Keban Baraj Gölü Pertek bölgesinde avlanabilen beş balık türünde $\% 74.97$ yaygınlık ile Diplostomum sp.,'nin baskın tür olduğunu bildirmiştir. Karatoy ve Soylu (2006), Durusu (Terkos) Gölü Çapak balıklarında yaptığı çalışmada Diplostomum sp.'’yi \%92.5 yaygınlık oranıyla dominant parazit olarak belirtmiştir. Aydoğdu ve ark. (2008), aynı parazitin Gölbaşı Baraj Gölü'ndeki
Eğrez balıklarında \%80.7 yaygınlık oranıyla baskın bulunan ikinci tür olduğunu bildirmiştir. Önceki çalışmalarda tatlı su balıklarında Diplostomum sp.,'nin yaygınlık oranı ile ilgili belirtilen sonuçlar, bu çalışmada belirlenen yaygınlık oranına benzerlik göstermektedir.

Çalışmamızda enfeste ettiği balık sayısı ve yaygınlığı bakımında ikinci dominant tür olarak $N$. rutili tespit edilmiştir. $N$. rutili $C$. trutta, L. barbus esocinus ve L. barbus mystaceus olmak üzere üç balık türünde tespit edilmiş olup, toplam yaygınlık oranı \%40,95, balıklardaki yaygınlık oranı ise sırasıyla \%69.38, \%44.64 ve \%50.94 olarak belirlenmiştir. Dörücü ve ark. (2008) Keban Baraj Gölü'nden avlanan $C$. turtta'da N. rutili tespit etmiş ve yaygınlığı \%71.43 olarak bildirmiştir. Kavak ve 
Şeker (2017) Keban Baraj Gölü'nde yaptıkları çalışmada $N$. rutili'nin toplam yayınlık oranını $\% 17.30$, C. trutta'daki yaygınlığını ise $\% 69.44$ olarak belirtmiştir. Koyun ve ark. (2019) Göynük Çayı'nda yaptıkları bir çalışmada C. trutta' da N. zabensis' i \%43.24 yaygınlık oranı ile dominant tür olarak tespit etmişlerdir. Ayrıca $C$. trutta' da tespit edilen N. zabensis' in Türk tatlısu balıklarında parazit faunası için ilk kayıt olduğu bildirilmiştir. Bu çalışmada ise C. turtta'da $N$ rutili'nin yaygınlığı \%69.38 olarak bulunmuş olup, bu sonuç Dörücü ve ark. (2008) ve Kavak ve Şeker (2017)'in çalışmalarının sonuçlarıyla benzerlik göstermiştir.

Çalışmamızda tespit edilen üçüncü parazit türü $K$. sinensis'e sadece $C$. carpio'da rastlanmış olup yaygınlık oranı \%15.38 olarak belirlenmiştir. Benzer şekilde, Kavak ve Şeker (2017) Keban Baraj Gölü Pertek bölgesinde avlanan balıklardan sadece C. carpio'da $K$. sinensis türüne rastlamış ve yaygınlığını \%2.56 olarak bildirmiştir. Keban Baraj Gölü'nde yapılan başka bir çalışmada ise $C$. carpio'da Khawia'ın farklı bir türü olan Khawia armenica tespit edilmiştir (Dörücü ve İspir, 2005).

\section{Sonuç ve Öneriler}

Sonuç olarak bu çalışmada, Diplostomum sp.,'nin incelenen dört balık türünün göz sıvısında bulunan dominant bir parazit olduğu ortaya konmuştur. Ayrıca N. rutili incelenen üç balık türünün bağırsağında yüksek oranlarda bulunmuştur. $K$. sinensis ise sadece $C$. carpio'nun bağırsağında düşük oranda tespit edilmiştir. Bu araştırmanın sonuçlarının, çalışma bölgesinde bundan sonra yapılacak parazitolojik çalışmalara kaynak oluşturacağı düşünülmektedir.

Teşekkür: Bu çalışma Munzur Üniversitesi Bilimsel Araştırma Projeleri Birimi (MÜNIBAP) tarafından YLTUB016-09 nolu proje olarak desteklenmiştir.

Çıkar Çatışması Beyanı: Makale yazarları aralarında herhangi bir çıkar çatışması olmadığını beyan ederler.

Araştırmacıların Katkı Oranı Beyan Özeti: Yazarlar makaleye eşit oranda katkı sağlamış olduklarını beyan ederler.

\section{Kaynaklar}

Arda, M., Seçer, S., Sarıeyyüpoğlu, M. 2005. Balık Hastalıkları. Medisan Yayın serisi. 61, II. Baskı Ankara 230s.

Aydoğdu, A., Emence, H., İnnal, D. 2008. Gölbaşı Baraj Gölü (Bursa)'ndeki Eğrez Balıkları (Vimba vimba L. 1758)'n da görülen helmint parazitler. Türkiye Parazitoloji Dergisi, 32 (1): 86-90.

Barata S, Dörücü M. 2014. Karakaya Baraj Gölü Kömürhan bölgesinden yakalanan bazı balık-larda endohelmintlerin araştırılması. Fırat Üniversitesi Fen Bilimleri Dergisi, 26 (1): 59-68.

Bush, A.O., Lafferty, K.D., Lotz, J.M. and Shostak, A.W. 1997. Parasitology meets ecology on its own terms, revised at Margolis J.Parasitology, 83 (4): 575-583.

Dörücü, M. ve İspir, Ü. 2005. Keban Baraj Gölü'nden avlanabilen balık türlerinde iç paraziter hastalıkların incelenmesi. Fırat Üniversitesi Fen ve Mühendislik Bilimleri Dergisi, 17(2): 400-404.

Dörücü, M., Dilsiz, N. and Grabbe, M.J. 2002. Occurrence and effects of Diplostomum sp. infection in eyes of Acanthobrama marmid in Keban Dam Lake, Elazig Turkey. Journal of Veterinary and Animal Sciences, 26 (2): 239-243.

Dörücü, M., Kan, N.İ. ve Öztekin, Z. 2008. Keban Baraj Gölü'nden avlanan bazı balık türlerinde iç parazitlerin incelenmesi. Journal of Fisheries Sciences, 2 (3): 484488.

Ekingen, G. 1983. Tatlı su balık parazitleri. Fırat Üniversitesi. Su Ürünleri Yüksek Okulu Yayınları, Elazığ, 253s.

Geldiay, R. ve Balık, S. 2007. Türkiye Tatlısu Balıkları. Ege Üniversitesi Su Ürünleri Fakültesi Yayınları No: 46, Ege Üniversitesi Basımevi, Bornova/ İzmir, 532s.

Hoffman, G.L. 1967. Parasites of North American Freshwater Fishes. University of California Press, Berkely and Los Angeles.

Hoole, D., Bucke, D., Burgess, P. and Wellby, L. 2001. Diseases of carp and other cyprinid fishes. First published USA and Canada, Lowa State University Press.

Karabulut, C. 2009. Keban Baraj Gölü'nde dört farklı bölgeden (Koçkale, Pertek, Çemişgezek, Keban) Avlanan Aynalı Sazan (Cyprinus carpio L., 1758)'da Endohelmintlerin Araştırılamsı. Fırat Üniversitesi, Fen Bilimleri Enstitüsü Biyoloji Anabilim Dalı, Yüksek Lisans Tezi, 29s.

Karatoy, E. ve Soylu, E. 2006. Durusu (Terkos) Gölü Çapak Balıkları (Abramis brama L., 1758)'nın metazoan parazitleri. Türkiye Parazitoloji Dergisi, 30 (3): 233-238.

Kavak, M. ve Şeker, E. 2017. Keban Baraj Gölü Pertek bölgesinden avlanabilen balıklarda endohelmintlerin araştırılması. Fırat 
Üniversitesi Fen Bilimleri Dergisi, 29(1): 3340.

Kennedy, C.R. 1974. A. checklist of British and Irish freshwater fish parasites with notes on their distribution. Journal of Fish Biology, 6:613-644.

Molnar, K. 1987. Solving parasite-related problems in cultured freshwater fish, International Journal for Parasitology, 17 (2): 319-326.

Özan, S., Kır, I., Ayvaz, Y. ve Barlas, M. 2006. Beyşehir Gölü Kadife Balığı (Tinca tinca L., 1758)'nın Parazitleri Üzerine Bir Araştırma. Türkiye Parazitoloji Dergisi, 30 (4): 333338.

Özdemir, Y. ve Sarıeyyüpoğlu, M. 1993. Some parasites of Barbus capito pectoralis cought in Keban Dam Lake. Firat Üniversitesi Fen ve Mühendislik Bilimleri Dergisi, 5 (2): 114-126.

Sağlam, N. 1991. Keban Baraj Gölü'nden Yakalanan Balıklarda Görülen External parazitlerin incelenmesi., Fırat Üniversitesi, Fen Bilimleri Enstitüsü, Su Ürünleri Anabilim Dalı, Yüksek Lisans Tezi, 50s.

Sağlam, N. ve Sarıeyyüpoğlu, M. 2002. Capoeta trutta balığında rastlanan Neoechinorhynchus
(Acanthocephala)'nin incelenmesi. Türkiye Parazitoloji Dergisi, 26: 329-331.

Sarıeyyüpoğlu, M. ve Sağlam, N. 1991. Keban Baraj Gölü'nün kirli bölgesinden yakalanan Capoeta trutta balıklarında görülen Ergasilus ieboldi ve Argulus foliaceus. Ege Üniversitesi Su Ürünleri Dergisi, 8 (31-32): 143-154.

Serdar, O., Pala, A. ve Küçükgül, A. 2018. Pülümür Akarsuyundan Avlanan Capoeta umbla (Heckel, 1843)'nın Sindirim Kanalı Helmintlerinin Araştırlması. International Journal of Pure and Applied Sciences, 4(1): 95-101.

Selver, M.M., Beyazıt, A., Tay, S. ve Tokşen, E. 2013. Sazan balığı (Cyprinus carpio L. 1758) yetiştiriciliği yapılan işletmelerde görülen helmintlerin araştırılması. Bornova Veteriner Bilimleri Dergisi 35 (49): 1-8.

Türk, C. ve Dörücü, M. 2000. Keban Baraj Gölü’nde Bulunan Acanthobrama marmid'lerde Görülen Ligula intestinalis (Cestoda: Pseudophllidea)'in Ekolojisi. Su Ürünleri Sempozyumu, (20-22 Eylül), Sinop. 